\title{
Detection of cesA mRNA from Bacillus cereus by RNA-specific amplification
}

\section{$\operatorname{AUTHOR}(\mathrm{S})$ :}

Yasukawa, Kiyoshi; Agata, Norio; Inouye, Kuniyo

\section{CITATION:}

Yasukawa, Kiyoshi ...[et al]. Detection of cesA mRNA from Bacillus cereus by RNA-specific amplification. Enzyme and Microbial Technology 2010, 46(5): 391-396

\section{ISSUE DATE:}

2010-04-05

URL:

http://hdl.handle.net/2433/120342

\section{RIGHT:}

(c) 2010 Elsevier B.V.; This is not the published version. Please cite only the published version.; この論文は出版社版でありません。引用の際に は出版社版をご確認ご利用ください。 
8385 GTCCAACGGTTATGAATGGTTATTTCAAAAATGATGAAGCAAATGCGGAAAGTTTTACTGAAGATGGCTGGTTCGATAGT 8465 GGAGATCTGGGGTTTATACATAACGGTAATCTTGTCATTACAGGAAGAAAAAAGGATATGATTGTTGTTCATGGTGCAAA 8545 TTACTACAACTATGAAATTGAAGCCTTGGTAGAACAAGTACCTGGGGTGGAAACCACGTTTGTATGTGCAACGAGTGTGA 8625 AGTCGGCTGAAGGAGCAGAGGAATTAGCTATTTTCTTTGTCCCAGTAATTAATCATGTTTCTGTGATGTTTGCGACGATG 8705 CAACAAATCAAACAAATTGTTGCGCGCAAAATGGTATCACGCCGAAAGTGATTATACCAATTCAGAAGGAAGCATTCTT 8785 TAAAACGGATAGTGGGAAAATAACGAGAAATGCATTTCAAAAACAGTTTGAGAACGGGGCATATAGAGAGATTACACAAA 8865 AGATTGATTGCCATTTACAAAATGAAAAAACACTATCTCAGTGGTTTTATCGTGAAAAATTAGTCGAAAGTAAGTTGGGC 8945 AAAAGCGTATCCTCCCAAAAAGAAACGTATGTTTTCTTTCGACAAGGTAAATCATTTCATCATGTCCTAAAAGAAAAGTT F8 9025 AACGCAACATTCTGTTGTTATTGTGGATGTAGGAGAAACATTCGGTGAGATCCATCCAAATCATTATCAAATTAATCCTA F9 9105 AAAACAAAATGGATTACGTTCGATTATTTGAAGAACTCGCAAAAAGAAATGTAGAAGATCAAGTTTTTCATCTCTTGCAT F10 9185 GCTTGGAATTATTGCGATACAGTTCCAACTTTTAGATCGGTAGAAGATTTAGCTAATGCGCAATATCTTGGTGTGTTAG 9265 TGTGATGTTCGCACTTCAAGCTATTATGCATGCGAATTGCCACTACGTCGTGTTACGGTGATTGCGACAAATAGTGTTG $\mathrm{R} 10$, P- R10 9345 gATTAGAAGCGAAGGAATGAA

B1 
A

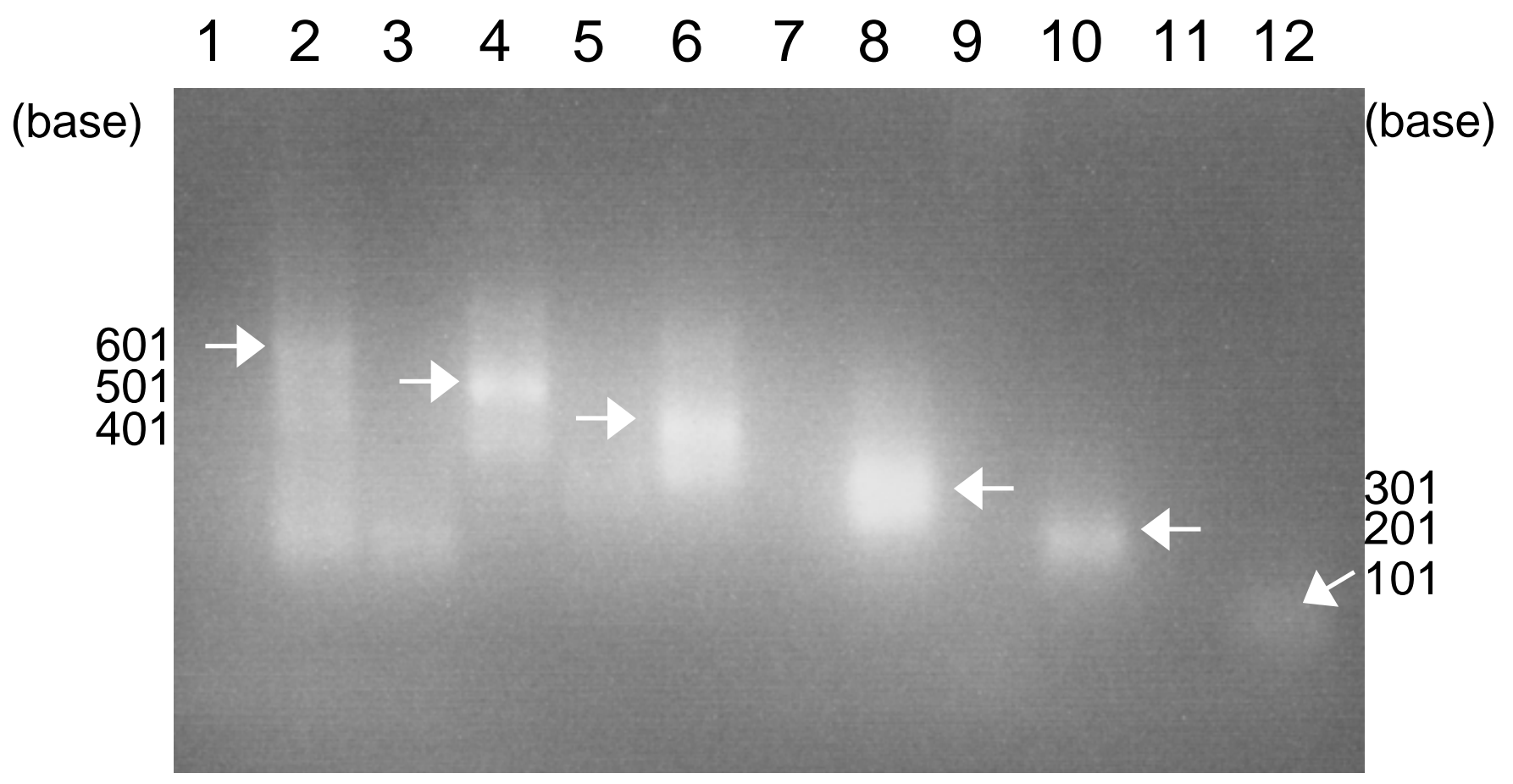

Fig. 2 


\section{B}
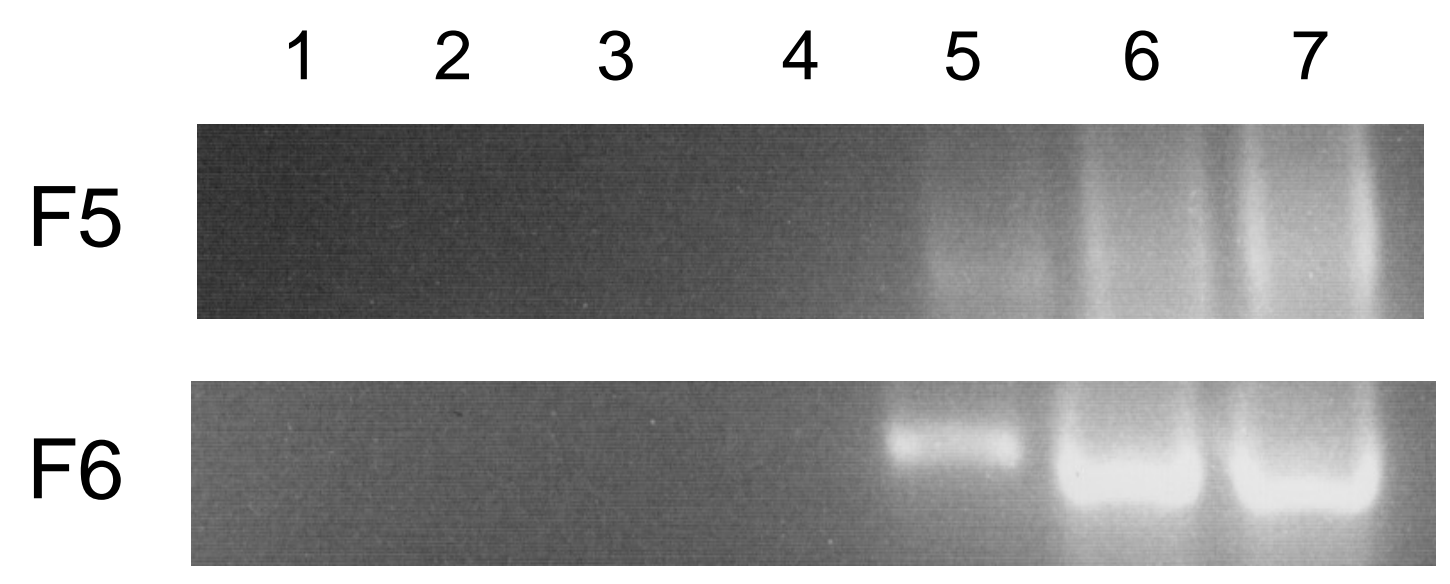

F7
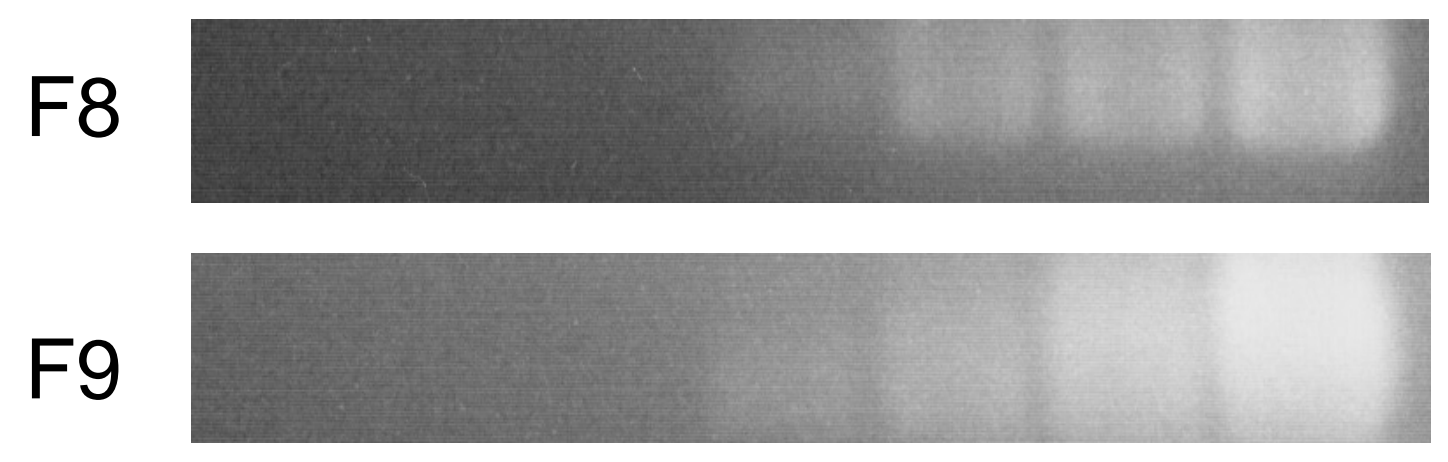

F10

Fig. 2 
C

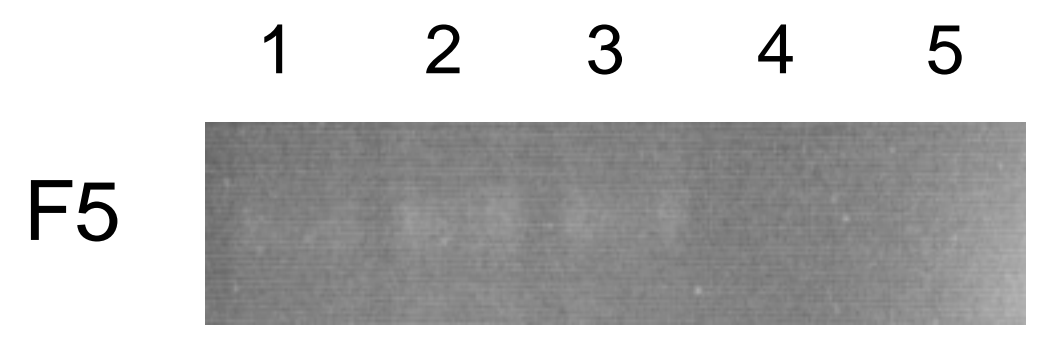

F6

F7

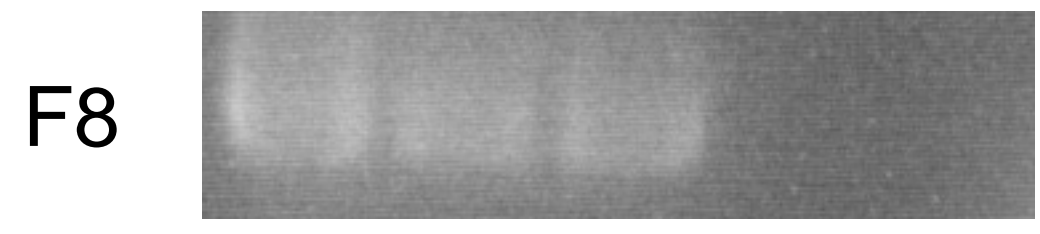

F9

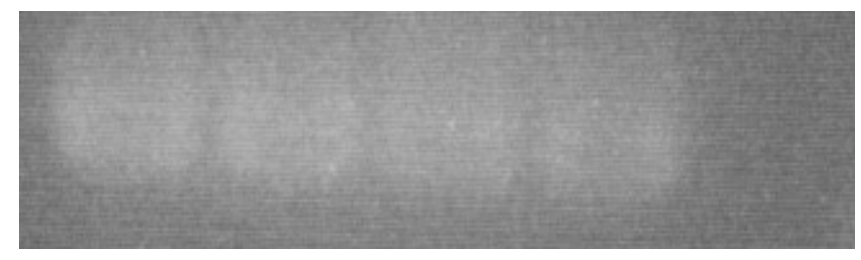

F10

Fig. 2 


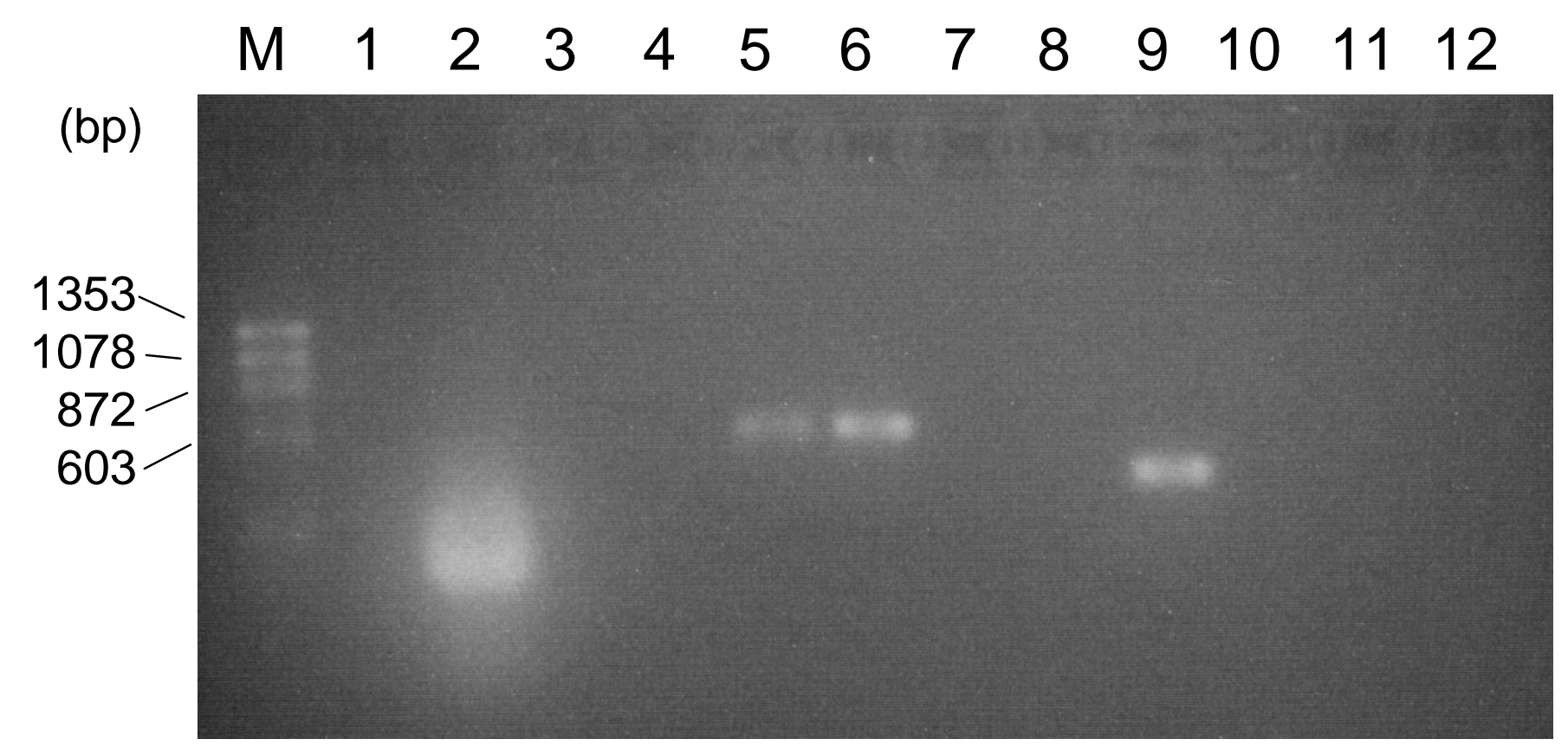

Fig. 3 